\title{
Primer Perkütan Koroner Girişim Yapılan ST-Segment Elevasyonlu Miyokard Enfarktüsünde MELD-Albumin Skorunun Prediktif Rolü
}

\section{The Predictive Role of MELD-Albumin Score in ST-Segment Elevation Myocardial Infarction Undergoing Primary Percutaneous Coronary Intervention}

\author{
$\underline{\text { Seckin DEREL }} 1{ }^{1}(\mathbb{D})$, Mustafa YENERÇAĞ 1 (D), Ahmet KAYA ${ }^{1}$ (D)
}

1 Ordu Üniversitesi Tıp Fakültesi, Kardiyoloji Anabilimdalı, Ordu, TÜRKIYE

Öz.

Amaç: Uluslararası normalleştirilmiş oranı (INR) hariç tutan modifiye Model for End-stage Liver Disease (MELD) skoru olan MELD-XI ile INR yerine albumin kullanan yine bir modifiye MELD skoru olan MELD-Albumin skorları karaciğer ve böbrek fonksiyonlarını yansıtır ve mortalitenin belirleyicileridir. Her ne kadar ST segment elevasyonlu miyokard enfarktüsü (STEMI) olan hastalarda MELD skoru çalışılmış olsa da, bu hasta grubunda MELD-XI ve MELD-Albumin skorlarının prediktif değerleri bugüne kadar çalışılmamıştır. Amacımız STEMI hastalarında MELDXI ve MELD-Albumin skorlarının mortalite üzerine prediktif değerini saptamaktı.

Materyal ve metod: Acil servise başvuran ve primer perkütan koroner girişim (pPKG) uygulanan 1506 ardışık STEMI hastası retrospektif olarak değerlendirildi. Prognoz için değerlendirilen parametreler başta hastane içi ve 12 aylık takipte mortalite ve diğer majör kardiyak olaylar (MACE) kabul edidi. Hastalar MELD-Albumin skoruna göre 5 gruba ayrıldı.

Bulgular: MELD-Albumin ve MELD-XI skorları yüksek olan hastalarda hastane içi ve 12 aylık mortalite anlamlı derecede yüksekti. Çoklu lojistik regresyon analizi ile MELD-XI ve MELD-Albumin skorlarının hastane içi ve 12 aylık mortalitenin öngördürücüleri olduğu tespit edildi. Receiver operating karakteristik analizi ile hem hastane içi hem de 12 aylık mortaliteyi öngördürmede modifiye MELD skorunun eğri altında kalan alanlarının (Area Under The Curve, AUC) MELD-Albumin skorunun AUC'sine göre daha yüksek olduğu saptandı.

Sonuç: MELD-Albumin skoru kolay hesaplanabilen, güvenilir ve pratik bir risk değerlendirme aracıdır. Bu skor, STEMI hastalarında hastane içi ve 12 aylık mortalitenin bağımsız bir ön gördürücüsüdür.

Anahtar Kelimeler: ST segment elevasyonlu miyokard enfarktüsü; Ölüm; Majör istenmeyen kardiyak olaylar; MELD-XI skor; MELD-Albumin skor;

\section{Abstract}

Background: The Model for End-stage Liver Disease excluding the international normalised ratio (INR, MELD$\mathrm{XI}$ ) and modified MELD, which uses albumin in place of the INR (MELD-Albumin) scores reflect liver and renal function and are predictors of mortality. Although MELD score has been studied in patients with ST-segment elevation myocardial infarction (STEMI), prognostic value of MELD-XI and MELD-Albumin scores has not been studied in those patients. Our aim was to determine the predictive value of MELD-XI and MELD-Albumin scores on mortality in patients with STEMI.

Materials and Methods: 1506 consecutive STEMI patients who applied to the emergency department and underwent primary percutaneous coronary intervention (PPCl) were evaluated retrospectively. The parameters evaluated for prognosis were primarily mortality and other major cardiac events (MACE) at in-hospital and 12month follow-up. Patients were stratified into 5 groups according to MELD-Albumin score.

Results: The patients with higher MELD-Albumin and MELD-XI scores had significantly higher in-hospital and long-term mortality. The multiple logistic regression analysis identified the MELD-XI and MELD-Albumin scores as the independent predictors of in-hospital and 12-month mortality. ROC curve analysis showed that area under curve (AUC)s of MELD-Albumin were higher than than MELD-XI AUCs for predicting mortality both in-hospital and at 12-month follow-up.

Conclusions: The MELD-Albumin score is an easily calculable, reliable, and practical risk assessment tool. This score may be used as an independent predictor of in-hospital and long-term mortality in patients with STEMI.

Key words: ST-elevation myocardial infarction; Mortality; Major adverse cardiac events; MELD-XI score; MELDAlbumin score

\section{Sorumlu Yazar I \\ Corresponding Author}

Seçkin DERELI

Ordu Üniversitesi Tıp Fakültesi

Kardiyoloji Anabilim dalı,

Ordu, TÜRKIYE

\section{Tel: +90 5333760984}

E-mail: drseckindereli@gmail.com

\section{Geliş tarihi / Received:}

28.06.2020

Kabul tarihi I Accepted: 23.11.2020

DOI: $10.35440 /$ hutfd. 759438 


\section{Giriş}

ST segment elevasyonlu miyokard enfarktüsü (STEMI), hastalığın prognozunu büyük ölçüde değiştiren güncel reperfüzyon stratejilerinin uygulanmasına rağmen hala kardiyovasküler hastalıklar arasında morbidite ve mortalitenin en başlıca nedenlerinden biri olarak yerini korumaktadır (1). STEMI hastalarında birincil amaç, hastanın başvuru anı riskine bakılmaksızın tıkanmış arterde zamanında yeniden akımı sağlamaktır $(2,3)$. Bununla birlikte, hastalarda hastane içi ve 12 aylık takipte prognozunun belirlenmesi için risk sınıflandırması önemlidir ve reperfüzyon sonrası girişimin sonuçlarını tahmin etmede ve hastaların yönetimini optimize etmede yardımcı olabilir (4). STEMI hastalarında risk sınıflandırması yapmak ve prognozu tahmin etmek için farklı biyobelirteçler kullanılmış ve yeni skorlama sistemleri geliştirilmiştir $(5,6)$.

Son zamanlarda, karaciğer ve böbrek fonksiyonunu yansıtan ve international normalized ratio (INR), total bilirubine ve kreatininine dayanan Model for End-stage Liver Disease (MELD) skoru, karaciğer ve kalp hastalarında prognostik bir belirleyici olarak yaygın olarak kullanılmaktadır (7-9). Ayrıca, antikoagülan kullanımı nedeniyle hesaplama sırasında INR'yi hariç tutan modifiye MELD skoru olan MELD-XI'nun çeşitli kardiyavasküler girişim sonuçlarını tahmin etmede yararlı olduğu doğrulanmıştır $(10,11)$. Ek olarak, INR yerine albümin serum değerini içeren MELDAlbumin skorunun kalp nakli ve çeşitli kalp kapağı girişimi sonrası klinik sonuçlarla ilişkili olduğu gösterilmiştir (12, 13). Bununla birlikte, primer perkütan koroner girişim (pPKG) uygulanan STEMI hastalarında bu 2 modifiye MELD skoru daha önce çalışılmamıştı. Çalışmamızın amacI, akut STEMI hastalarında MELD-XI ve MELD-Albumin skorlarının major istenmeyen kardiyak olaylar için prediktif rollerini değerlendirmektir.

\section{Materyal ve Metod}

Ocak 2015 ve Aralık 2019 arasında, üçüncü basamak hastanenin acil servisine başvuran ve pPKG uygulanan 1506 ardışık STEMI hastası retrospektif olarak değerlendirildi. Aşağıdaki kriterlere göre STEMI tanısı konan tüm hastalar çalışmaya dahil edildi: (a) 30 dakikadan fazla süren tipik göğüs ağrısı olması (b) Elektrokardiyografide (EKG) en az iki ardışık derivasyonda olmak üzere V2-3 derivasyonlarında 40 yaş altı erkeklerde $0.25 \mathrm{mV}, 40$ yaş üstü erkeklerde $0.25 \mathrm{mV}$ veya kadınlarda $0.15 \mathrm{mV}$ ve / veya diğer derivasyonlarda ise $0.1 \mathrm{mV}$ ST segmenti elevasyonu veya yeni gelişmiş olduğu kesin ya da muhtemel bir sol dal bloğu tespit edilmesi (14). Yukarıda belirtilen kriterlerin karşılanıp karşılanmadığını doğrulamak için tüm EKG hasta dosyalarından veya hastanenin elektronik veritabanından taranmıştır. EKGsi tespit edilemeyen ve/veya MELD skorlarını hesaplamak için verileri eksik olan hastalar çalışma dışı bırakıldı. Eksik verisi olan 123 hasta, karaciğer sirozu öyküsü olan 6 hasta, sağ ventrikül dilatasyonu / yetmezliği ve orta şiddette ciddi triküspit yetersizliği olan 38 hasta analizden çıkarıldı. Ek olarak, uzun vadede sağkalımı doğrulamak için temas kurulamayan 55 hasta (veya hasta yakınları) çalışma dışı bırakııdı. Bu dahil etme ve hariç tutma kriterlerini uyguladıktan sonra 222 hasta çalışma dışı bırakılarak 1506 hasta ile çalışma tamamlanıldı. Çalışma Helsinki Bildirgesi'ne uygundur. Ordu Üniversitesi Klinik Araştırmalar Etik Kurulu tarafindan 12/03/2020 tarihli toplant-sında 45 karar sayısı ile onaylanmıştır.

Hastane veri tabanından ve hasta dosyalarından yaş, cinsiyet gibi demografik veriler ile hipertansiyon $(\mathrm{HT})$, diabetes mellitus (DM), hiperlipidemi $(\mathrm{HL})$ gibi risk faktörleri ve klinik geçmiş tarandı. HT 140 mmHg'den yüksek sistolik basınç veya $90 \mathrm{~mm} H \mathrm{Hg}^{\prime}$ den yüksek diyastolik basınç veya antihipertansif ilaçların kullanımı olarak tanımlandı. DM ise başvuruda herhangi bir oral antidiyabetik ajan veya insülin kullanımı veya yatışta ölçülen aşağıdaki laboratuvar değerlerinden herhangi biri olarak tanımlandı: açlık glikozu 126 mg/dL (en az iki ölçüm) veya HbA1c \%6.5 den yüksek ölçülmesi. HL, kabulden önce oral antihiperlipidemi kullanımı veya yatışta ölçülen aşağıdaki laboratuvar değerlerinden herhangi biri olarak tanımlandı: serum toplam kolesterol $240 \mathrm{mg} / \mathrm{dL}$, serum trigliserit $200 \mathrm{mg} / \mathrm{dL}$ ve düşük yoğunluk lipoprotein kolesterol $130 \mathrm{mg} / \mathrm{dL}$ üzerinde olması. Her hasta için tıbbi veri tabanından hastaneye kabuldeki venöz kan örneklerinden elde edilen laboratuar değerleri kaydedildi. Tüm hastaların yattığı dönemdeki ekokardiyografi kayıtları incelenildi ve kaydedildi.

Önceki çalışmalara dayanarak United Network for Organ Sharing tarafından kabul gören modifiye MELD skorlarını kullandık (15). Negatif skorları önlemek için tüm değişkenlerin alt sınırı 1.0 olarak ve kreatinin için üst sınır $4.0 \mathrm{mg} /$ dl olarak belirlendi. MELD-XI skoru, aşağıdaki formülü kullanarak hesaplandl: 5.11xln (total bilirubin,mg/dl) + 11.76x $\ln$ (creatinine, $\mathrm{mg} / \mathrm{dl})+9.44$. Negatif skorlardan kaçınmak için, toplam bilirubin ve kreatinin alt limiti formüllerde $1.0 \mathrm{mg} / \mathrm{dL}$ olarak kabul edildi. Serum albumin $\geq 4.1$ $\mathrm{g} / \mathrm{dL}$ ise MELD-Albumin skoru bu formül kullanılarak hesaplandl: $11.2 \times \ln (1)+3.78 x \ln$ (total bilirubin, $\mathrm{mg} / \mathrm{dl})+9.57 x \ln$ (serum kreatin, $\mathrm{mg} / \mathrm{dl}$ )+ 6.43. Serum albu$\min <4.1 \mathrm{~g} / \mathrm{dL}$ olduğunda ise, MELD-Albumin skoru, aşağıdaki formüle göre hesaplandı:11.2x $\ln [1+(4.1$-albumin)] + 3.78xIn (total bilirubin, $\mathrm{mg} / \mathrm{dl}$ )+9.57x/n (kreatin, $\mathrm{mg} / \mathrm{dl}$ ) + 6.43 .

Tüm koroner anjiyografi ve PPKG prosedürleri deneyimli girişimsel kardiyologlar tarafından transfemoral yaklaşımla gerçekleştirildi. STEMI için pPKG, güncel kılavuzlara göre gerçekleştirildi (3). Koroner arter hastalığı (KAH) tanısı tüm hastalarda koroner anjiyografi ile doğrulandı ve önemli bir hastalı̆ıın belgelenmesinden oluştu (ana koroner arterlerden en az birinde veya enfarktla ilişkili düşünülen arterde $\geq \% 50$ lümen daralması olarak tanımlandı). Çok damar hastalığı ise, iki veya daha fazla epikardiyal koroner ar- 
terde $\geq \% 50$ lümen daralması olarak tanımlandı. Hastaların anjiyografik verileri kateter laboratuvar kayıtlarından değerlendirildi. Stent tipi ve trombektomi cihazlarının kullanımı, predilatasyon, postdilatasyon, glikoprotein Ilb/llla inhibitörlerinin seçimi gibi periprosedürel tercihlerin tümü operatörlerin takdirine bırakılmıştı. Hem aspirin $(100 \mathrm{mg} /$ gün) hem de klopidogrel (75 mg / gün) veya prasugrel (10 $\mathrm{mg} /$ gün) veya tigakrelor (günde iki kez $90 \mathrm{mg}$ ) en az 12 ay boyunca ikili antiplatelet tedavi uygulandı. Beta-blokerler, anjiyotensin dönüştürücü enzim inhibitörleri ve statinler gibi farmakolojik tedavi, hastaneye yatış sırasında ve taburculukta Avrupa Kardiyoloji Derneği (ESC) kılavuzlarına göre uygulandı.

Hastane içi ölüm, hastaneden taburcu edilmeden önce herhangi bir nedenden ötürü ölüm olarak tanımlanırken, 12 aylık ölüm ise taburculuk sonrası 12 ay içinde herhangi bir nedenden ötürü ölüm olarak tanımlandı. Ek olarak stent trombozu, akut solunum yetmezliği, akut böbrek yetmezliği, rekürren miyokard infarktüsü, inme/geçici iskemik atak (TIA) ve hedef damar revaskülarizasyonu (TVR) takiplerde değerlendirildi. Miyokardiyal reenfarktüs, miyokard enfarktüsünün üçüncü evrensel sınıflamasına göre tanımlandı (16). TVR, başlangıçta tedavi edilen arteri içeren by-pass cerrahisi dahil herhangi bir revaskülarizasyon prosedürü olarak tanımlandı. İnme/TIA, yakın tarihli iskemi veya hemoraji olayla uyumlu kranial görüntülemenin eşlik ettiği akut nörolojik defisit gelişmesi olarak tanımlandı. Kanama olayları Akademik Araştırma Konsorsiyumu tanı kriterleri kullanılarak tanımlanmıştır. Ölüm ve diğer major istenmeyen kardiyak olayları değerlendirilmesi hastanenin tıbbi veri tabanı, e-Nabız ugulaması kullanılarak veya takip görüşmeleriyle (doğrudan poliklinik veya telefonla) yapıldı.

İstatistiksel analiz

Veriler SPSS 23 (SPSS Inc, Chicago, IL, USA) paket program ile değerlendirildi. Normal dağılıma uyan sürekli değişkenler ortalama \pm standart sapma şeklinde, normal dağlııma uymayan sürekli değişkenler medyan $(0,25-0,75$ persentil) şeklinde, kategorik değişkenler ise yüzde olarak ifade edildi. Çalışma populasyonu MELD-Albumin skorundaki artışa göre beş alt gruba sınıflandıııldı. Normal dağıIıma uyan beş bağımsız grubun parametrik değişkenleri Bonferroni içeren / içermeyen ANOVA testi ile karşılaştırılırken, normal dağılıma uymayan beş grubun parametrik değişkenleri Bonferroni düzeltmeli / düzeltmesiz Kruskal Wallis-H testi ile karşılaştırıldı. Kategorik değişkenler Kikare testi ile karşılaştırıldı. MELD-XI ve MELD-Albumin skorlarının hastane içi ve 12 aylık takipteki ölümü öngördürme kapasitesi Receiver Operating Characteristics (ROC) eğrisi analizi kullanılarak analiz edildi. MELD skorlarının eğri altında kalan alanlarının (AUC) karşılaştırmaları MedCalc istatistiksel yazılımı (Delong testi) ile yapıldı. Hastane içi ve 12 aylık mortalitenin bağımsız prediktörlerini belirlemek için, tek değişkenli analizlerde tüm nedenlere bağlı ölüm oranıyla anlamlı ilişki gösteren değişkenler kullanılarak, aşamalı geriye dönük bir modelle çok değişkenli bir Cox regresyon analizi gerçekleştirildi. 0.05'ten küçük iki taraflı p değeri anlamlı kabul edildi.

\section{Bulgular}

MELD-Albumin skoruna göre ayrılan gruplarının demografik, klinik ve sonuç değişkenleri Tablo 1 'de verilmiştir. MELD-Albumin skoru arttıkça gruplardaki hastalar daha yaşı idi ve kadın cinsiyet sıklığı giderek artmaktaydı (her ikisi için $p<0.001$ ). Risk fakörleri açısından karşılaştıııldığında $H L$ dışında $(p=0.530)$ diğer risk faktörlerinin MELDAlbumin skoru yüksek olan gruplarda daha sık oranda izlendiği gözlendi (hepsi için $p<0.001$ ). Daha düşük MELDAlbumin skoru olan gruplara kıyasla yüksek olanlarda kreatinin, bilirubin düzeyleri daha yüksek ve glomeruler filtrasyon hızı ile hemoglobin değerleri daha düşüktü . (hepsi için $p<0.001)$. Sol ventrikül ejeksion fraksiyonu karşılaştıııldığında MELD-Albumin skoru yüksek gruplarda daha düşük izlendi $(p<0.001)$.

MELD-Albumin skoruna göre sınıflandırımış grupların anjiyografik ve prosedürel özellikleri Tablo 2'de verilmişir. Koroner anjiyografi parametrelerinde MELD-Albumin skoru yüksek olan gruplarda safen ven greft darlığı ve üç damar hastalığı anlamlı olarak daha yüksekti (her ikisi için $p$ $<.001$ ). Bununla birlikte, MELD-Albumin skorunun yüksek olduğu gruplarda kalp yetmezliği insidansının yüksek olması nedeniyle loop diüretik ve spironolakton kullanımı daha sık gözlendi (her ikisi için $p<.001$ ). Revaskülarizasyon sıklığı gruplar arasında MELD-Albumin skoru yüksek gruplarda daha yüksek izlenmiştir. MELD-Albumin kategorileri ile hastane içi ve 12 aylık takipte ölüm arasında dereceli bir ilişki vardı, ancak risk en çok 4. ve 5. gruplardaydı. Hastaneye yatış sırasında, hastane içi ölüm, kardiyojenik şok, stent trombozu, tekrarlayan miyokard enfarktüsü, hedef lezyon revaskülarizasyonu, akut solunum yetmezliği, akut böbrek yetmezliği ve inme/geçici iskemik atak (TIA) skorun yüksek olduğu gruplarda anlamlı derecede yüksekti $(p<0.001)$ (Tablo 3). Hastaneye yatıştan sonra, 12 aylık takip sırasında, tüm nedenlere bağlı ölüm, stent trombozu, tekrarlayan miyokard enfarktüsü ve hedef lezyon revaskülarizasyon insidansı Q5'tekiler için en yüksekti ve diğer tüm gruplardan anlamlı olarak daha sık izlendi (tümü için $p 0<.001$ ) (Tablo 4).

Hastane içi ve 12 aylık takipte mortalitenin bağımsız prediktörlerini belirlemek için, tek değişkenli analizlerde tüm nedenlere bağlı ölüm oranıyla anlamlı ilişki gösteren değişkenler kullanılarak, aşamalı geriye dönük bir modelle çok değişkenli bir Cox regresyon analizi gerçekleştirildi. Bu değişkenler Tablo 5 ve 6'te gösterilmektedir. MELD-XI ve MELD-Albumin skorları çok değişkenli analiz sonucunda hem hastane içi hem takipte mortalitenin güçlü prediktörleri olarak bulunmuştur. 
Tablo 1. MELD-Albumin skoruna göre sınıflandırılmış grupların temel özellikleri

\begin{tabular}{|c|c|c|c|c|c|c|}
\hline Parametreler & Q1 (n:339) & Q2 (n:421) & Q3 (n:282) & Q4 (n:139) & $\begin{array}{l}\text { Q5 } \\
\text { (n:103) }\end{array}$ & $p$ \\
\hline Yaş (yıl) & $49.4 \pm 6.9$ & $56.5 \pm 8.3$ & $63.5 \pm 7.9$ & $68.6 \pm 8.1$ & $75.3 \pm 8.6$ & $<.001$ \\
\hline Erkek cinsiyet $(n, \%)$ & $285(84.3)$ & $348(82.7)$ & $218(77.4)$ & $102(73.6)$ & 67 (65.4) & $<.001$ \\
\hline $\operatorname{VKI}\left(\mathrm{kg} / \mathrm{m}^{2}\right)$ & $27.8 \pm 4.2$ & $28.0 \pm 3.6$ & $27.9 \pm 2.9$ & $28.1 \pm 3.5$ & $28.0 \pm 3.1$ & 0.650 \\
\hline MELD-XI skoru & $5.3(2.8-7.5)$ & $7.9(5.1-12.3)$ & $13.2(11.6-16.7)$ & $14.7(11.3-17.5)$ & $18.4(15.1-27.3)$ & - \\
\hline MELD-Albumin skoru & $4.9(2.5-7.2)$ & $6.8(4.8-10.7)$ & $13.1(9.9-15.6)$ & $17.9(15.3-21.3)$ & $26.1(22.6-29.8)$ & - \\
\hline \multicolumn{7}{|c|}{ Risk faktörleri n,\% } \\
\hline Hipertansiyon & $63(18.7)$ & $104(24.7)$ & $80(28.3)$ & $42(30.3)$ & $33(32.4)$ & $<.001$ \\
\hline Diyabet & $69(20.4)$ & $106(25.3)$ & $81(28.7)$ & $43(30.5)$ & $34(33.9)$ & $<.001$ \\
\hline Hiperlipidemi & $99(29.4)$ & $105(25.0)$ & $76(27.5)$ & $40(28.8)$ & $28(27.7)$ & 0.530 \\
\hline KBH & $22(6.5)$ & $375(8.9)$ & $30(10.5)$ & $26(18.6)$ & $26(25.6)$ & $<.001$ \\
\hline PCl öyküsü & $52(15.4)$ & $45(20.6)$ & $74(26.3)$ & $40(29.1)$ & $33(32.3)$ & $<.001$ \\
\hline CABG öyküsü & $9(2.8)$ & $22(5.4)$ & $22(7.6)$ & $12(8.5)$ & $10(9.7)$ & $<.001$ \\
\hline \multicolumn{7}{|c|}{ Başvuru zamanı } \\
\hline SKB (mmHg) & $140.0 \pm 23.7$ & $135.7 \pm 26.3$ & $130.0 \pm 27.3$ & $125.5 \pm 24.7$ & $118.9 \pm 22.1$ & $<.001$ \\
\hline DKB (mmHg) & $77.8 \pm 14.7$ & $73.8 \pm 13.6$ & $70.5 \pm 13.6$ & $67.4 \pm 11.6$ & $64.6 \pm 10.8$ & $<.001$ \\
\hline Anterior MI $(n, \%)$ & $139(40.7)$ & $17(39.8)$ & $120(42.5)$ & $59(42.7)$ & $42(41.6)$ & 0.330 \\
\hline Killip klas 3-4 $(n, \%)$ & $12(3.5)$ & $23(5.6)$ & $23(8.1)$ & $139(9.9)$ & $17(16.3)$ & $<.001$ \\
\hline SVEF (\%) & $47.5 \pm 8.9$ & $46.6 \pm 10.8$ & $44.7 \pm 10.2$ & $45.0 \pm 11.6$ & $43.6 \pm 12.6$ & $<.001$ \\
\hline Kapı balon zamanı (dakika) & $20.2 \pm 10.3$ & $19.6 \pm 9.1$ & $20.3 \pm 9.3$ & $20.1 \pm 10.5$ & $20.3 \pm 9.9$ & 0.603 \\
\hline \multicolumn{7}{|c|}{ Labaratuar parametleri } \\
\hline Kreatinin (mg/dL) & $0.83 \pm 0.19$ & $0.89 \pm 0.25$ & $0.98 \pm 0.39$ & $1.18 \pm 0.63$ & $1.44 \pm 1.3$ & $<.001$ \\
\hline Hemoglobin (g/dL) & $14.4 \pm 1.6$ & $13.9 \pm 1.5$ & $13.3 \pm 1.6$ & $12.8 \pm 1.7$ & $12.1 \pm 1.3$ & $<.001$ \\
\hline GFR (mL/min) & $121 \pm 42.8$ & $109 \pm 30.4$ & $90.3 \pm 26.5$ & $83.5 \pm 27.6$ & $63.1 \pm 24.5$ & $<.001$ \\
\hline Lökosit (cells/mL) & $11.1 \pm 3.9$ & $10.9 \pm 5.2$ & $11.3 \pm 4.0$ & $10.9 \pm 4.2$ & $11.20 \pm 4.3$ & 0.290 \\
\hline Trombosit (cells/mL) & $246 \pm 63$ & $239 \pm 69$ & $241 \pm 65$ & $243 \pm 74$ & $238 \pm 57$ & 0.405 \\
\hline Albumin $(\mathrm{g} / \mathrm{dL})$ & $4.1 \pm 0.6$ & $4.2 \pm 0.5$ & $4.0 \pm 0.6$ & $3.9 \pm 0.4$ & $3.8 \pm 0.4$ & 0.055 \\
\hline T.Bilirubin (mg/dL) & $0.57(0.40-0.78)$ & $0.60(0.40-0.90)$ & $0.82(0.73-1.02)$ & $0.91(0.69-1.13)$ & $1.03(0.79-1.42)$ & $<.001$ \\
\hline CRP (mg/dL) & $4.88 \pm 1.50$ & $5.16 \pm 1.46$ & $0.60 \pm 0.22$ & $0.54 \pm 0.18$ & $0.50 \pm 0.12$ & 0.698 \\
\hline Pik CK-MB (ng/mL) & $139 \pm 134$ & $137 \pm 142$ & $138 \pm 152$ & $143 \pm 149$ & $144 \pm 162$ & 0.069 \\
\hline Pik troponin I (ng/L) & 51(19.9-97.5) & $59(23.3-115.5)$ & $74.6(37.1-156.6)$ & $82.2(38.4-187)$ & $150.3(65.1-265.6)$ & 0.003 \\
\hline \multicolumn{7}{|c|}{ Kılavuz önerisi tedavi n,\% } \\
\hline ACEI\&ARB & $320(94.6)$ & $392(93.2)$ & $263(93.5)$ & $129(92.9)$ & $95(94.5)$ & 0.450 \\
\hline Tirofiban & 255 (75.3) & $305(72.5)$ & $195(69.1)$ & $101(72.8)$ & $68(67.4)$ & 0.003 \\
\hline Beta bloker & $300(88.6)$ & $265(86.6)$ & $243(86.2)$ & $121(87.2)$ & $91(90.3)$ & 0.152 \\
\hline Statin & $273(80.6)$ & $353(83.8)$ & $235(83.2)$ & $111(80.0)$ & $81(80.1)$ & 0.090 \\
\hline Diuretik & $23(7.5)$ & $42(10.0)$ & $32(11.3)$ & $17(12.5)$ & $16(15.4)$ & $<.001$ \\
\hline Spironolakton & $61(18.0)$ & $88(21.0)$ & $70(24.8)$ & $52(37.0)$ & $39(38.9)$ & $<.001$ \\
\hline Takip süresi (ay) & $15.2 \pm 3.5$ & $15.1 \pm 4.7$ & $14.3 \pm 6.8$ & $13.2 \pm 8.6$ & $12.2 \pm 7.6$ & $<.001$ \\
\hline
\end{tabular}

Değişkenler ortalama \pm standart sapma şeklinde veya sayı (\%) olarak normal dağı̆ıma uymayan değişkenler ise ortanca (minimum-maksimum) olarak ifade edilmişstir. MELD: Model for End-stage Liver Disease; PCl: Perkutan koroner girişim; CABG: Koroner bypass cerrahisi; PTCA: Perkütan translüminal anjioplasti; ACEl: Anjiotensin dönüştürücü enzim inhibitörü; ARB: Anjiotensin reseptör blokeri;

Tablo 2. MELD-Albumin skoruna göre sınıflandırılmış grupların anjiyografik ve prosedürel özellikleri

\begin{tabular}{|c|c|c|c|c|c|c|}
\hline \multicolumn{7}{|c|}{ Sorumlu koroner ARTER $\mathrm{n}, \%$} \\
\hline Sol ana koroner & $2(0.6)$ & $3(0.8)$ & $2(0.8)$ & $9(0.7)$ & $10(0.9)$ & 0.891 \\
\hline Sol ön inen arter & $170(50.1)$ & $190(45.2)$ & $130(46.4)$ & $60(43.5)$ & $42(41.3)$ & .008 \\
\hline Sirkümfleks arter & $47(14.0)$ & $68(16.3)$ & $38(13.4)$ & $23(16.6)$ & $16(15.9)$ & .198 \\
\hline Sağ koroner arter & $115(34.0)$ & $151(35.9)$ & $103(36.5)$ & $48(35.1)$ & $36(36.1)$ & .106 \\
\hline Safen ven grefti & $5(1.3)$ & $7(1.8)$ & $81(2.9)$ & $6(4.1)$ & $6(5.8)$ & $<.001$ \\
\hline \multicolumn{7}{|c|}{ Kritik damar sayısı (>50\%) n,\% } \\
\hline 1 damar & $223(66.0)$ & $235(55.8)$ & $140(49.5)$ & $65(47.0)$ & $39(38.5)$ & $<001$ \\
\hline 2 damar & $77(22.7)$ & $108(25.6)$ & $76(27.5)$ & $39(28.1)$ & $31(30.0)$ & $<001$ \\
\hline 3 damar & $38(11.3)$ & $78(18.6)$ & $65(23.0)$ & $35(24.9)$ & $32(31.5)$ & $<.001$ \\
\hline \multicolumn{7}{|c|}{ Stent tipi $n, \%$} \\
\hline İlaç salınımlı stent & $217(63.9)$ & $268(63.6)$ & $169(60.0)$ & $74(53.5)$ & $56(55.4)$ & 0.001 \\
\hline Çıplak metal stent & $36(10.5)$ & $45(10.7)$ & $28(9.9)$ & $13(9.2)$ & $8(7.6)$ & 0.003 \\
\hline
\end{tabular}

Değişkenler ortalama \pm standart sapma şeklinde veya sayı (\%) olarak normal dağılıma uymayan değişkenler ise ortanca (minimum-maksimum) olarak ifade edilmiştir. MELD: Model for End-stage Liver Disease; 
Tablo 3. MELD-Albumin skoruna göre sınıflandırılmış grupların hastane içi major kardiyak olaylar açısından karşılaştıııması

\begin{tabular}{|l|l|l|l|l|l|l|}
\hline Parametreler $\mathrm{n}, \%$ & $\mathrm{Q} 1(\mathrm{n}: 339)$ & $\mathrm{Q} 2(\mathrm{n}: 421)$ & $\mathrm{Q} 3(\mathrm{n}: 282)$ & $\mathrm{Q} 4(\mathrm{n}: 139)$ & $\mathrm{Q} 5(\mathrm{n}: 103)$ & $\mathrm{p}$ \\
\hline Tüm nedenlere bağlı ölüm & $7(2.1)$ & $16(3.7)$ & $11(4.1)$ & $15(10.6)$ & $31(30.7)$ & $<.001$ \\
\hline Kardiyojenik şok & $8(2.3)$ & $12(2.8)$ & $9(3.2)$ & $9(6.8)$ & $13(12.8)$ & $<.001$ \\
\hline Stent trombozu & $8(2.4)$ & $15(3.5)$ & $16(5.8)$ & $10(7.3)$ & $14(13.7)$ & $<.001$ \\
\hline Rekürren miyokard infarktüsü & $10(2.9)$ & $18(4.3)$ & $19(6.6)$ & $13(9.2)$ & $14(13.7)$ & $<.001$ \\
\hline Hedef lezyon revaskülarizasyonu & $10(2.9)$ & $15(3.5)$ & $20(7.2)$ & $14(10.2)$ & $12(11.3)$ & $<.001$ \\
\hline Akut solunum yetmezliği & $6(1.9)$ & $11(2.7)$ & $10(3.6)$ & $9(6.8)$ & $10(9.5)$ & $<.001$ \\
\hline Akut böbrek yetmezliği & $30(8.8)$ & $48(11.5)$ & $38(13.6)$ & $20(14.2)$ & $20(19.4)$ & $<.001$ \\
\hline İnme/geçici iskemik atak (TIA) & $16(4.8)$ & $25(5.9)$ & $19(6.9)$ & $10(7.3)$ & $21(12.4)$ & $<.001$ \\
\hline
\end{tabular}

Değişkenler yüzde (\%) olarak ifade edilmiştir. MELD: Model for End-stage Liver Disease;

Tablo 4. MELD-Albumin skoruna göre sınıflandırılmış grupların 12 aylık takip major kardiyak olaylar açısından karşılaştırılması

\begin{tabular}{|l|l|l|l|l|l|l|}
\hline Parametreler $\mathrm{n}, \%$ & $\mathrm{Q} 1(\mathrm{n}: 339)$ & $\mathrm{Q} 2(\mathrm{n}: 421)$ & $\mathrm{Q} 3(\mathrm{n}: 282)$ & $\mathrm{Q} 4(\mathrm{n}: 139)$ & $\mathrm{Q} 5(\mathrm{n}: 103)$ & $\mathrm{p}$ \\
\hline Tüm nedenlere bağlı ölüm & $10(3.0)$ & $13(3.2)$ & $16(5.8)$ & $13(9.5)$ & $22(21.9)$ & $<.001$ \\
\hline Stent trombozu & $15(4.5)$ & $15(3.4)$ & $14(4.9)$ & $9(6.8)$ & $13(12.3)$ & $<.001$ \\
\hline Rekürren miyokard infarktüsü & $22(6.5)$ & $24(5.7)$ & $24(8.4)$ & $13(9.2)$ & $16(15.1)$ & $<.001$ \\
\hline Hedef lezyon revaskülarizasyonu & $21(6.4)$ & $26(5.8)$ & $21(7.5)$ & $15(10.6)$ & $13(12.8)$ & $<.001$ \\
\hline
\end{tabular}

Değişkenler yüzde (\%) olarak ifade edilmiştir. MELD: Model for End-stage Liver Disease;

Tablo 5. Çok değişkenli regresyon analizinde hastane içi mortalitenin prediktörleri

\begin{tabular}{|l|l|l|l|l|}
\hline & Unadjusted OR & $\mathbf{P}$ & Adjusted OR & P \\
\hline Yaş & $1.040(1.015-1.065)$ & 0.002 & $1.014(0.982-1.048)$ & \\
\hline Erkek cinsiyet & $1.165(0.703-1.931)$ & 0.552 & & \\
\hline Diyabet & $1.715(1.018-2.886)$ & 0.041 & $1.350(0.763-2.389)$ & \\
\hline Sigara & $1.099(0.638-1.892)$ & 0.733 & & 0.296 \\
\hline Ejeksiyon fraksiyonu & $1.333(1.225-1.450)$ & 0.004 & $1.081(1.009-1.157)$ & \\
\hline Killip sınIfI & $1.006(0.982-1.032)$ & $<0.001$ & $1.003(0.966-1.040)$ & 0.024 \\
\hline MELD-XI skoru & $1.035(1.009-1.062)$ & 0.002 & $1.031(1.009-1.054)$ & $<0.001$ \\
\hline MELD-Albumin skoru & $5.260(3.054-9.059)$ & $<0.001$ & $4.274(2.390-7.643)$ & 0.001 \\
\hline
\end{tabular}

MELD: Model for End-stage Liver Disease; OR: Odds oranı

Tablo 6. Çok değişkenli regresyon analizinde 12 aylık takipte mortalie prediktörleri

\begin{tabular}{|l|l|l|l|l|}
\hline & Unadjusted OR & P & Adjusted OR & P \\
\hline Yaş & $1.078(1.049-1.126)$ & 0.025 & $1.048(1.027-1.086)$ & 0.126 \\
\hline Erkek cinsiyet & $0.764(0.169-3.459)$ & 0.562 & & \\
\hline Diyabet & $1.123(1.087-1.166)$ & 0.006 & $1.475(1.368-1.803)$ & \\
\hline Sigara & $0.764(0.169-2.396)$ & 0.492 & & 0.044 \\
\hline Ejeksiyon fraksiyonu & $0.474(0.276-0.833)$ & 0.006 & $0.569(0.279-0.802)$ & 0.018 \\
\hline Killip sinff & $1.006(0.982-1.032)$ & $<0.001$ & $1.003(0.966-1.040)$ & $<0.001$ \\
\hline MELD-XI skoru & $1.035(1.009-1.062)$ & 0.002 & $1.031(1.009-1.054)$ & 0.001 \\
\hline MELD-Albumin skoru & $2.395(1.421-4.035)$ & 0.001 & $2.129(1.229-3.690)$ & 0.007 \\
\hline
\end{tabular}

MELD: Model for End-stage Liver Disease; OR: Odds oranı

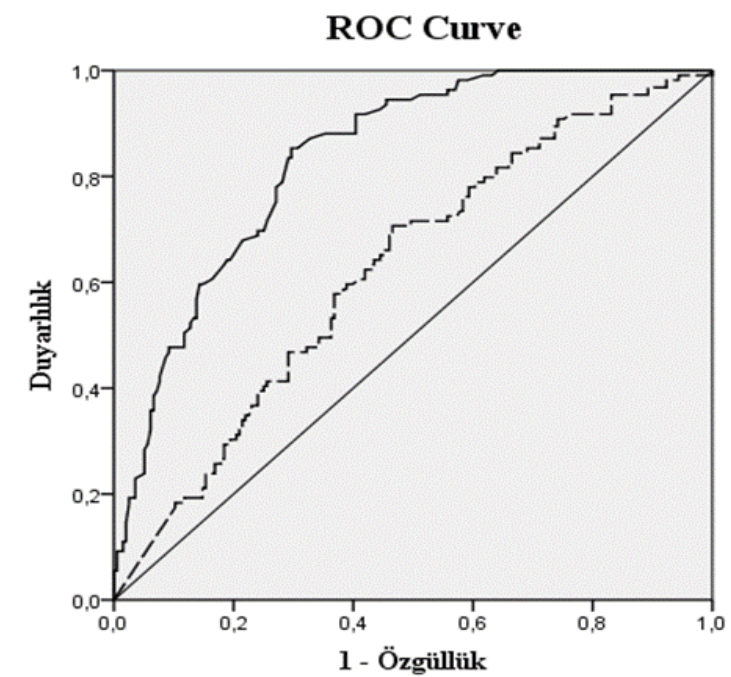

\section{- MELD-Albumin skorv \\ -- MELD-XI skoru}

MELD-Albumin MELD-XI

AUC SE \%95 CI

$\begin{array}{llll}A U C & \text { SE } & \% 95 \mathrm{CI}\end{array}$

$\begin{array}{llll}0.711 & 0.019 & 0.669-0.762\end{array}$

Şekil 1. Hastane içi mortaliteyi tahmin etmek için MELD-XI ve MELD-Albumin skorlarının Receiver operating characteristic (ROC) curve analizi 


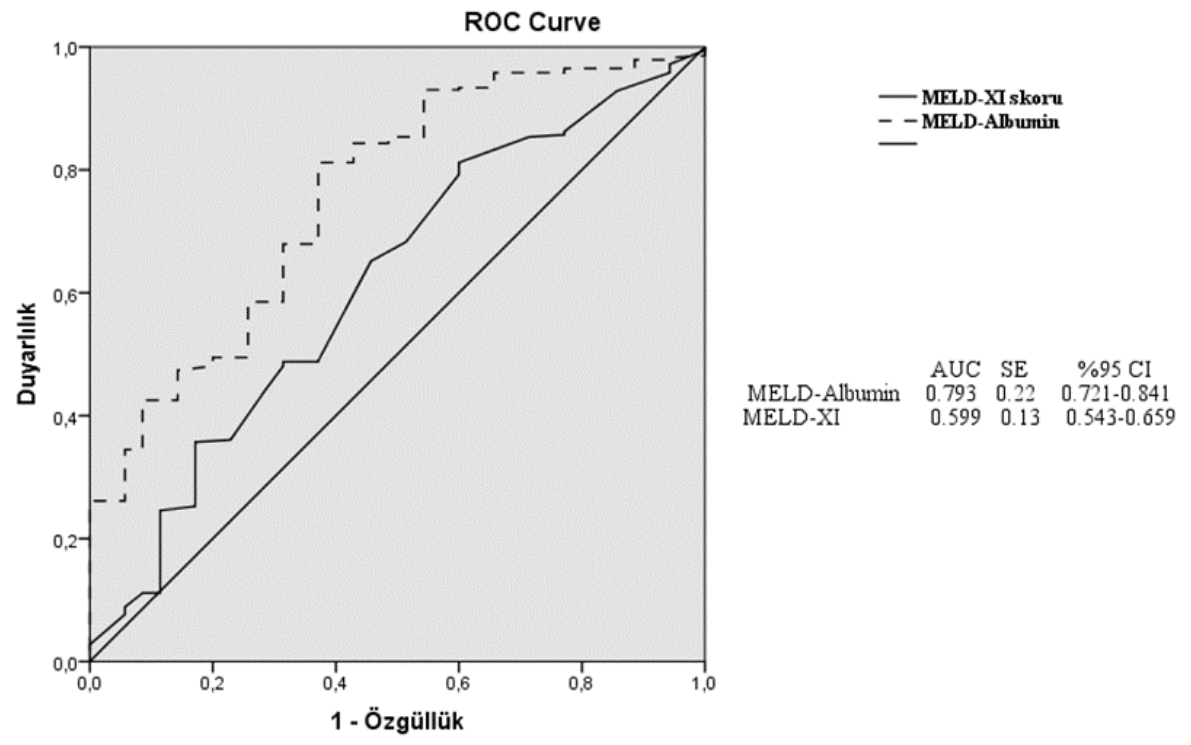

Şekil 2. 12 aylık takipte mortaliteyi tahmin etmek için MELD-XI ve MELD-Albumin skorlarının Receiver operating characteristic (ROC) curve analizi

ROC analizinde; hastane içi ölüm için MELD-Albumin ve MELD-XI skorlarının AUC değerleri sırasıyla 0.831 (\%95 Cl: 0.799-0.869, $\mathrm{p}=0.001$ ) ve 0,711 (\%95 Cl: 0.669-0.762, $\mathrm{p}=0.001$ ) olarak bulunurken (Şekil 1) 12 ay takipte ölüm için AUC değerleri ise 0.793 (\%95 Cl: 0.721-0.841, $\mathrm{p}=0.001)$ ve 0.599 (\%95 Cl: $0.543-0.659, \mathrm{p}=0.001)$ olarak bulunmuştur (Şekil 2). Hastane içi mortaliteyi tahmin etmek için MELD-XI skorunun en iyi cut-off değeri \% 63 sensitivite ve\% 69 spesifite ile 15.7 iken MELD-Albumin skoru için $\% 73$ sensitivite ve $\% 78$ spesifite ile 14.9 olarak saptanilmıştır. 12 aylık takipteki mortalite tahmini için ise MELDXI skorunun en iyi cutoff değeri \% 59 sensitivite ve\% 61 spesitive ile 14.8 iken MELD-Albumin için ise $\% 69$ sensitivite ve $\% 74$ spesitive ile 14.1 idi. Bu analizde, MELD-Albuminin hem hastane içi hem 12 ay takipte ölüm tahmininde belirgin prediktif güce sahip olduğu gösterilmiştir.

\section{Tartışma}

Bildiğimiz kadarıyla bu çalışma, STEMI tanısı ile pPKG uygulanan hastalarda MELD-XI ve MELD-Albumin skorlarlnın, standart klinik ve demografik parametrelerin ötesinde, mortalite ile anlamlı derecede ilişkili olduğunu gösteren ilk çalışmadır.

Karaciğer sirozu olan hastalarda risk sınıflaması için hem karaciğer hem de böbrek fonksiyonunu (total bilirubin, kreatinin ve INR'ye dayanarak) yansıtan MELD skoru geliştirilmiştir (17). Son araştırmalarda, skorun farklı kardiyovasküler hastalıklarda ve kalp nakli de dahil olmak üzere çeşitli kardiyak girişimlerde prognostik değere sahip olduğunu gösterilmiştir (18-21). Hemoglobin katabolizmasının son ürünü bilirubin eskiden beri atık ürün olarak görülmekle birlikte, şu anda reaktif oksijen radikallerini azaltma ve düşük yoğunluklu lipoprotein kolesterolün oksidasyonunu önleme kapasitesine sahip güçlü bir endojen antioksidan olarak kabul edilmektedir (22). Son dönemdeki çalışmalar serum bilirubin düzeyleri ile KAH prevalansı veya ciddiyeti arasında negatif bir ilişki olduğunu bildirmektedir (23). Sağlıklı popülasyonda yapılan çalışmalarda yüksek serum bilirubin düzeyleri düşük Framingham risk skorları ile ilişkili bulunmuştur (24). pPKG uygulanan STEMI hastalarında yapılan çaIsşmada ise bilirubinin noreflow ve hastane içi MACE ile bağımsız olarak ilişkili olduğunu gösterilmiştir. Bir başka çalışmada ise bilirubin düzeyleri NSTEMI'li hastalarda koroner arter hastalığının şiddeti ile ilişkili bulunmuştur (25). Bizim çalışmamızda da bilirubin formülasyonunda yer aldığı MELD türevi skor ölümün bağımsız prediktörü olarak bulunmuştur.

Bununla beraber kardiyovasküler hastalıklarda komorbidite olarak atrial fibrilasyon prevelansı yüksektir ve tedavide antikogülan sıkça kullanılmaktadır (26). Antikoagülan kullanıldığı durumlarda INR değerlendirmesini içeren MELD skorunun doğruluğu tartışmalıdır. MELD-XI ve MELD-Albumin skorları, antikoagülan reçete edilen hastalarda hepatik fonksiyonları daha iyi yansıtabilmek için INR değerlendirmesini hariç tutmak için özel olarak tasarlanmışlardır (21, 27, 28). Kırış ve ark. çalışmasında MELD skor, ölüm görülen STEMI hastalarında anlamlı derecede yüksek bulunmuşken (29) bizim çalışmamızda da hastalarda MELD-Albumin skorunun yüksek olduğu gruplarda ölüm anlamlı derecede yüksek izlendi ve MELD-Albumin ölüm ve MACE için bağımsız prediktör olarak saptanmıştır. Ayrıca MELD-Albumin skorunun, Meld-XI skoruna göre çaIışmamızda mortalite için eğri değerinin altında daha yüksek bir alana ve daha iyi kalibrasyona sahip olması dikkat çekicidir . Bu sonuç ek risk bilgisi sağlamak amacıyla serum albümininin modifiye MELD skoruna dahil edilmesini 
desteklemektedir. Gerçekten de, albümin, karaciğer tarafından üretilen önemli bir salgı proteinidir. STEMI kliniğinde karaciğerde oluşabilecek göreceli hipoksi, iskemi ve pasif venöz konjesyon sonucunda hipoksik hepatit izlenebilir ve albümin sentezinde düşüşle sonuçlanabilir bu hipotezi destekler nitelikte albuminin de hesaplamada kullanıldığı skorlar STEMI hastalarında çeşitli çalışmalarda kullanılmış ve ölüm izlenen hasta gruplarında farklı bulunmuştur (30-33). Çalışmamızda elde ettiğimiz veriler ışığında, MELD-XI ve MELD-Albumin skorlarının STEMI hastalarınnın tanı koyulduğunda risk sınıflandırması için değerli olabileceği varsayılabilir. Çünkü bu skorların hesaplanması çok daha kolaydır, Killip sınıflaması gibi subjektif ve gözlemciye bağlı klinik değerlendirmeye tabi değildir. TIMI risk skoru ise hastaya yapılan ilk müdahele sonucunda sonucunda kolayca etkilenebilir çünkü değişken kan basıncı, kalp atış hızı ve oksijenasyon gibi parametrelerden oluşur $(34,35)$. Rutin laboratuvar testleriyle kolayca ve ucuz bir şekilde ölçülebilen ve iki kritik organ sistemini yansıtan üç parametreye dayandığından, MELD-Albumin skoru özellikle yüksek riskli STEMI hastalarında sağlam ve pratik bir başucu risk değerlendirme aracı olarak görülebilir. Bununla beraber doğru risk sınıflandırması için en uygun cutoff value yu belirlemek için daha larger çalışmalar gereklidir.

Çalışmamızın bazı kısıtıııklarının olduğunu biliyoruz. Birincil kısıttıı̆̆ı az sayıda hasta ile yapılan retrospektif gözlemsel bir çalışma olmasıdır. Zaman aralığındaki değerlerden ziyade acil servise başvuru anında spot laboratuvar değeri kullanmak bu çalışmanın başka bir sınırlamasıdır. Çalışmaya dahil olan merkezlerin hiçbirinde trombolitik tedavi dışında cerrahi veya kateter embolektomi gibi başka tedavi seçenekleri yoktu, bu nedenle alternatif tedavi seçeneklerinin etkilerini karşılaştıramadık. Ayrıca, gama-glutamiltransferaz, sistatin $C$ ve kidney injury molecule-1 gibi yeni karaciğer ve böbrek biyobelirteçleri ölçülmedi. Bizim çalışmamızda sağ ventrikül disfonksiyonu veya sağ ventrikül dilatasyonu olan hastalar çalışma dışı bırakııldı. Bu nedenle, sağ ventrikül ile ilişkili hepatik disfonksiyon değerlendirilmedi. Mevcut çalışma, önceki ağırlıklı olarak cerrahi literatürde bildirilen klinik durumdan farklı bir klinik ortam olan STEMI hastalarını içerdiğinden MELD skorlarında farklılık buluanabilir. Bu nedenle, STEMI'Iı hastalarda MELD-Albumin skorunun prognostik performansını ve optimal kesme değerlerini doğrulamak için daha geniş örneklem büyüklüğüne sahip daha fazla çalışmaya intiyaç vardır.

Bu çalışmanın bulguları pPKG uygulanan STEMI hastalarında yüksek MELD skorları ile ölüm riski arasında güçlü bir ilişki olduğunu göstermiştir. MELD-Albumin, analiz edilen tüm hasta alt grupları dahil olmak üzere hastane içi ve 12 aylık takipte ölüm için MELD-XI'den daha üstün bulundu. Mevcut bulgulara dayanarak, MELD-Albumin skorunun STEMI hastalarında mortalite için klinik rutinde ucuz ve pratik bir prediktör olarak kullanılabileceği düşünülebilir.
Etik Kurul Onayı: Ordu Üniversitesi Klinik Araştırmalar Etik Kurulu tarafindan 12/03/2020 tarihli toplantısında 45 karar sayısı ile onaylanmıştır.

\section{Kaynaklar}

1. Nichols M, Townsend N, Scarborough P, Rayner M. Cardiovascular disease in Europe: epidemiological update. Eur Heart $\mathrm{J}$. 2013;34(39):3028-34.

2. Puymirat E, Simon T, Steg PG, Schiele F, Guéret $P$, Blanchard D, et al. Association of changes in clinical characteristics and management with improvement in survival among patients with ST-elevation myocardial infarction. JAMA. 2012;308(10):998-1006.

3. Steg PG, James SK, Gersh BJ. 2012 ESC STEMI guidelines and reperfusion therapy: Evidence-based recommendations, ensuring optimal patient management. Heart. 2013;99(16):1156-7.

4. Brkovic V, Dobric M, Beleslin B, Giga V, Vukcevic V, Stojkovic S, et al. Additive prognostic value of the SYNTAX score over GRACE, TIMI, ZWOLLE, CADILLAC and PAMI risk scores in patients with acute STsegment elevation myocardial infarction treated by primary percutaneous coronary intervention. Int J Cardiovasc Imaging. 2013;29(6):121528.

5. Chiostri M, Valente S, Crudeli E, Giglioli C, Gensini GF. A new post$\mathrm{PCl}$ scoring system for in-hospital mortality in STEMI patients. J Cardiovasc Med. 2010;11(10):733-8.

6. Keskin M, Güvenç TS, Hayıroğlu Mi, Kaya A, Tatısu MA, Avşar Ş, et al. A novel prognostic indicator for in-hospital and 4-year outcomes in patients with pulmonary embolism: TIMI risk index. J Crit Care. 2017;41:183-90.

7. Deo SV, Al-Kindi SG, Altarabsheh SE, Hang D, Kumar S, Ginwalla $\mathrm{MB}$, et al. Model for end-stage liver disease excluding international normalized ratio (MELD-XI) score predicts heart transplant outcomes: evidence from the registry of the United Network for Organ Sharing. J Heart Lung Transplant.. 2016;35(2):222-7.

8. Srikureja W, Kyulo NL, Runyon BA, Hu K-Q. MELD score is a better prognostic model than Child-Turcotte-Pugh score or Discriminant Function score in patients with alcoholic hepatitis. J Hepatol. 2005;42(5):7006.

9. Çiftci O, Çelik ÇO, Uzar G, Küpeli E, Müderrisoğlu IH. MELD-XI score predicts in-hospital mortality independent of simplified pulmonary embolism severity index among patients with intermediate-to-high risk acute pulmonary thromboembolism. Tuberk Toraks. 2019 Sep;67(3):169-178.

10. Abe S, Yoshihisa A, Takiguchi M, Shimizu T, Nakamura Y, Yamauchi $\mathrm{H}$, et al. Liver dysfunction assessed by model for end-stage liver disease excluding INR (MELD-XI) scoring system predicts adverse prognosis in heart failure. PloS one. 2014;9(6):e100618.

11. Inohara T, Kohsaka S, Shiraishi Y, Goda A, Sawano M, Yagawa M, et al. Prognostic impact of renal and hepatic dysfunction based on the MELD-XI score in patients with acute heart failure. Int J Cardiol. 2014;176(3):571-3.

12. Moraes ACO, Fonseca-Neto OCLD. The use of MELD score (Model for end-stage liver disease) and derivatives in cardiac transplantation.. Arq Bras Cir Dig. 2018;31(2):e1370.

13. Grimm JC, Magruder JT, Do N, Spinner JA, Dungan SP, Kilic A, et al. Modified model for end-stage liver disease excluding INR (MELD-XI) score predicts early death after pediatric heart transplantation. Ann Thorac Surg. 2016;101(2):730-5.

14. Ibanez B, James S, Agewall S, Antunes MJ, Bucciarelli-Ducci C, Bueno H, Caforio ALP, et al. ESC Scientific Document Group. 2017 ESC Guidelines for the management of acute myocardial infarction in patients presenting with ST-segment elevation: The Task Force for the management of acute myocardial infarction in patients presenting with ST-segment elevation of the European Society of Cardiology (ESC). Eur Heart J. 2018 Jan 7;39(2):119-77.

15. Unos.org [homepage on the Internet]. MELD/PELD Calculator Documentation April 21, 2013 [updated January 28, 2009. Available from: 
https://www.unos.org/wp-content/uploads/unos/MELD_PELD_Calculator_Documentation.pdf

16. Bax JJ, Baumgartner $\mathrm{H}$, Ceconi $\mathrm{C}$, Dean V, Fagard R, Funck-Brentano $\mathrm{C}$, et al. Third universal definition of myocardial infarction. J Am Coll Cardiol. 2012;60(16):1581-98.

17. Habib S, Berk B, Chang CCH, Demetris AJ, Fontes P, Dvorchik I, et al. MELD and prediction of post-liver transplantation survival. Liver Transpl. 2006;12(3):440-7.

18. Chokshi A, Cheema FH, Schaefle KJ, Jiang J, Collado E, Shahzad $\mathrm{K}$, et al. Hepatic dysfunction and survival after orthotopic heart transplantation: application of the MELD scoring system for outcome prediction. J Heart Lung Transplant.. 2012;31(6):591-600.

19. Kim MS, Kato TS, Farr M, Wu C, Givens RC, Collado E, et al. Hepatic dysfunction in ambulatory patients with heart failure: application of the MELD scoring system for outcome prediction. J Am Coll Cardiol. 2013;61(22):2253-61.

20. Arai T, Yashima F, Yanagisawa R, Tanaka M, Shimizu H, Fukuda $\mathrm{K}$, et al. Prognostic value of liver dysfunction assessed by MELD-XI scoring system in patients undergoing transcatheter aortic valve implantation. Int J Cardiol. 2017;228:648-53.

21. Chen Y, Liu YX, Seto WK, Wu MZ, Yu YJ, Lam YM, et al. Prognostic value of hepatorenal function by modified model for end-stage liver disease (MELD) score in patients undergoing tricuspid annuloplasty. J Am Heart Assoc. 2018;7(14):e009020.

22. Shibahara S. The heme oxygenase dilemma in cellular homeostasis: new insights for the feedback regulation of heme catabolism. Tohoku J Exp Med. 2003;200(4):167-86.

23. Vítek $L$. The role of bilirubin in diabetes, metabolic syndrome, and cardiovascular diseases. Front Pharmacol. 2012;3:55.

24. Kim K-M, Kim B-T, Park S-B, Cho D-Y, Je SH, Kim K-N. Serum total bilirubin concentration is inversely correlated with Framingham risk score in Koreans. Arch Med Res. 2012;43(4):288-93.

25. Şahin Ö, Akpek M, Karadavut S, Coşgun MS, Savaş G, Şarlı B, et al. Relation between Serum Total Bilirubin Levels and Severity of Coronary Artery Disease in Patients with Non ST Elevation Myocardial Infarction. J Am Coll Cardiol. 2013;62(18 Supplement 2):C217-C8.

26. De Caterina R, Husted S, Wallentin L, Agnelli G, Bachmann F, Baigent $C$, et al. Anticoagulants in heart disease: current status and perspectives. Eur Heart J. 2007;28(7):880-913.

27. Wernly B, Lichtenauer M, Franz M, Kabisch B, Muessig J, Masyuk $M$, et al. Model for End-stage Liver Disease excluding INR (MELD-XI) score in critically ill patients: Easily available and of prognostic relevance. PloS one. 2017;12(2):e0170987.

28. Biegus J, Zymliński R, Sokolski M, Siwołowski P, Gajewski P, Nawrocka-Millward $S$, et al. Impaired hepato-renal function defined by the MELD XI score as prognosticator in acute heart failure. Eur J Heart Fail. 2016;18(12):1518-21.

29. Kırıs T, Avcı E, Çelik A. Combined value of left ventricular ejection fraction and the Model for End-Stage Liver Disease (MELD) score for predicting mortality in patients with acute coronary syndrome who were undergoing percutaneous coronary intervention. BMC Cardiovasc Disord. 2018;18(1):44.

30. Omer FC, Ahmet OA, Ahmet SY, Sinan Ş, Ali RA. Cirakoglu OF, Aslan AO, Yilmaz AS, Şahin S, Akyüz AR. Association Between C-Reactive Protein to Albumin Ratio and Left Ventricular Thrombus Formation Following Acute Anterior Myocardial Infarction. Angiology. Angiology. 2020 Oct;71(9):804-11.

31. Jia Y, Gao Y, Li D, Cao Y, Cheng Y, Li F, et al. Geriatric Nutritional Risk Index Score Predicts Clinical Outcome in Patients With Acute STSegment Elevation Myocardial Infarction. J Cardiovasc Nurs. 2020 Nov/Dec;35(6):E44-E52.

32. Tascanov MB, Güngören F. Akut Koroner Sendromlu Hastalarda Plazma von Willebrand Faktör Düzeyi ile Koroner Arter Hastalığı Ciddiyeti Arasındaki İlişkisi. Harran Üniversitesi Tıp Fakültesi Dergisi 2019;16(3):421-25.
33. Ekrem A, Deniz A, Çıkım G, Çelik Y. Tip II Diyabetes Mellituslu Hastalarda Serum Ürik Asit Ve Gama Glutamil Transferaz Düzeyleri Ile Koroner Arter Hastalığı Gelişimi Arasındaki liş̧ki. Journal of Harran University Medical Faculty. 2016;13(3):231-6.

34. Killip T 3rd, Kimball JT. Treatment of myocardial infarction in a coronary care unit. A two year experience with 250 patients. Am J Cardiol. 1967 Oct;20(4):457-64.

35. Morrow DA, Antman EM, Charlesworth A, Cairns R, Murphy SA, de Lemos JA, et al. TIMI risk score for ST-elevation myocardial infarction: a convenient, bedside, clinical score for risk assessment at presentation: an intravenous $\mathrm{nPA}$ for treatment of infarcting myocardium early II trial substudy. Circulation. 2000;102(17):2031-7. 